\title{
Revista Aisthesis y el desarrollo de la estética en Chile
}

\author{
César Zamorano Díaz \\ Facultad de Letras, Pontificia Universidad Católica de Chile. \\ cesarzamo33@gmail.com
}

El campo artístico o literario es un campo de fuerzas, pero es también un campo de batalla, tendiente a transformar o conservar este campo de fuerzas.

Pierre Bourdieu

\begin{abstract}
La noción de época puede pensarse como 'las condiciones para que surja un objeto de discurso', es decir, el espacio de lo decible en un momento y en un lugar dados. Las revistas, al tiempo que buscan traspasar esa frontera, se someten a ellas. Para el estudioso de la época, ése es el lineamiento principal del trabajo con revistas, particularmente cuando la palabra se vuelve objeto de interdicción o control, cuando aparecen en primer plano problemas de táctica, estrategia y alineamiento. ¿Cómo saber qué es lo que se calla"
\end{abstract}

Claudia Gilman

\section{Introducción ${ }^{1}$}

Bien sabemos desde Nietzsche, y luego con Foucault, que la inscripción de saberes y sus construcciones disciplinarias, definidas para componer una modalidad de prácticas y su teorización, responden a tiempos que, pensados genealógicamente, nos permiten reconocer sus avatares en su propia emergencia y modificaciones singulares. De este modo, la inscripción de los saberes como campo de fuerzas constituye con Bourdieu

1 Este trabajo forma parte del proyecto de investigación Postdoctoral FondECYT-Conicyt № 3150496 "Revistas culturales en Chile (1970-1990) y la conformación de un campo cultural". 
un gesto nietzscheano que permite mirar cómo se construyen los ideales, principios y valores que cada disciplina y campo cultural define. Sin duda que la proliferación de saberes y sus institucionalizaciones requieren una larga historia que va desde una periferia, propuestas teóricas, modos de abordar y repartir lo sensible, hasta la constitución de un conjunto de referencias e ideas que terminan definiendo un campo con una cierta autonomía. Los procesos de articulación de estas maduraciones teóricas pueden contener los impulsos de un grupo o tendencia arraigada y potenciada desde una dependencia histórica mediada y condenada por su propia contingencia. Otras veces, siempre en su contingencia, las propuestas conllevan un objeto o una posibilidad de hacer y decir que trasciende en el tiempo; y sus registros, en su obstinada perduración, acaban definiendo una disciplina. Es el caso de la estética como categoría filosófica que ha sido capaz de articular su propio espacio de delimitación de un corpus de problemas relativos al arte.

No es intención de estas páginas dar cuenta de la especificidad de la práctica estética y su independencia o filiación difusa con la filosofía en la cual se inserta. Su tratamiento, sin duda, no alcanzaría siquiera a abarcar un diagnóstico superficial de su mera práctica y algunas filiaciones conceptuales, desde las cuales podríamos derivar su propio cuerpo teórico. Aunque pudiéramos hacer esto, no lograríamos más que complejizar el propio objeto artístico, que ha modificado no solo sus prácticas, sino también las formas de concebir lo que llamamos arte. Desde esta limitación, para evitar excesivas generalizaciones, este trabajo propone recomponer someramente el desarrollo de la estética como corpus de pensamiento en torno al arte articulado desde el espacio de la revista chilena Aisthesis. Esto nos permitirá delimitar el lugar desde donde se articula nuestra reflexión y, al mismo tiempo, circunscribir la notoriedad de su práctica en un doble registro espacial y temporal, esto es, en su carácter local y global, en su contingencia y permanencia.

\section{Estudio de las revistas}

Aunque actualmente se ha incrementado la investigación en torno a las revistas como centros neurálgicos de producción y distribución de conocimiento; durante mucho tiempo, estas fueron desplazada por ser consideradas expresiones "secundarias". En los últimos años, las revistas han constituido una fuente prolífica de material que permite comprender el establecimiento de redes culturales en contextos específicos; gracias a esto, ha surgido una amplia recopilación en ediciones facsimilares de revistas perdidas en anaqueles y bibliotecas. Pero la investigación ha tendido no solo a la recopilación, sino sobre todo a reconocer el valor de estas revistas como aparatos culturales que ayudan a entender los procesos que dieron fruto a tendencias, ideas políticas y teóricas, campos culturales, cánones literarios o estéticos, y problemáticas de corto o largo alcance, precarias en el tiempo o permanentes hasta nuestros 
días. Las revistas, por tanto, pueden ser vistas como el espacio disponible en torno a las cuales se diseñan complejas relaciones entre cultura y política, entre proyectos estético-culturales y su intervención en el imaginario colectivo y social. En definitiva, este corpus constituye un material privilegiado para comprender redes culturales, movimientos estéticos, literarios y políticos que tuvieron mayor o menor resonancia en el devenir latinoamericano.

Es en las revistas en donde podemos observar cómo y cuáles son las relaciones que constituyen un campo intelectual, entendido como un espacio social, relativamente autónomo, de producción de bienes simbólicos. Las revistas nos permiten visibilizar el sistema de relaciones que configuran las coordenadas más o menos específicas de problemas, fronteras disciplinarias y circulación de saberes que, de acuerdo con Bourdieu, constituyen todo un "inconsciente cultural" (10). En este mismo sentido, para Beatriz Sarlo, fundadora de Punto de Vista (1978-2008), una de las revistas culturales más importantes y longevas de Argentina, ellas "son un lugar y una organización de discursos diferentes, un mapa de las relaciones intelectuales, con sus clivajes de edad e ideologías, una red de comunicación entre la dimensión cultural y la política" (15). Por lo mismo es que las revistas, de acuerdo con Schwartz y Patiño, pueden ser "pensadas como un espacio dinámico de circulación e intersección de discursos altamente significativos para el estudio no solo de la literatura sino del análisis, la historia y la sociología cultural, la historia de las ideas y la historia intelectual, entre otros campos" (647).

El carácter contingente, profundamente arraigado en un tiempo específico, constitutivo del carácter dialógico de las revistas, o en palabras de Fernanda Beigel, todos estos textos "preñados de contexto" (110), nos obliga a reconocer la imperiosa necesidad de reconstruir su tiempo-espacio específico a la hora de abordar las revistas. En este sentido, el interés por dar cuenta de la trayectoria de una revista como Aisthesis supone considerar las disciplinas como construcciones históricas constituidas por objetos en litigio. En nuestro caso, siguiendo a Rancière, "nos interesamos entonces en las formas de percepción, en los actos intelectuales y las decisiones que presidieron la formación de esas pequeñas repúblicas [disciplinas], en la constitución de sus objetos, sus reglamentos y sus fronteras" (6).

\section{Época de formación y revolución}

Aisthesis, Revista Chilena de Investigaciones Estéticas, inició su publicación en 1966 como modo de expresión del recién formado Centro de Investigaciones Estéticas (1964), fundado por el destacado esteta e investigador croata radicado en Chile, Doctor Raimundo Kupareo. A partir de este centro, surge, en 1972, el Bachillerato en Estética, perteneciente a la Facultad de Filosofía de la Pontificia Universidad Católica de Chile. Desde entonces, la revista ha sido publicada casi ininterrumpidamente hasta 
la actualidad. ${ }^{2}$ Hasta su número 38 en 2005 , la revista se lanzaba una vez al año para posteriormente aparecer en forma bianual, contando en la actualidad con la longevidad casi extinta de cincuenta años de trayectoria dedicada a la conformación de la estética y a una identidad particular que la distingue de otras producciones sobre arte al interior de la práctica filosófica. Como toda revista institucional, destinada a constituir un campo de estudio específico y potenciar la distribución de saberes desarrollados en las casas de estudios e instituciones académicas a las cuales pertenecen, su historia es también la historia de una práctica concreta desarrollada por el Instituto de Estética de la Universidad, lo que supone que su estudio es al mismo tiempo el tránsito, las perplejidades y las filiaciones que la revista ha tenido y sigue teniendo en relación con los tiempos en los cuales se inserta. Por tener una prolongada vida, recorrer sus páginas es también transitar por los procesos sociales e históricos que han calado hondo en las prácticas académicas en Chile y que es preciso delimitar.

Los lineamientos de la revista implicaron desde su origen abordar en detalle una praxis artística específica que dio profundidad y experticia a sus planteamientos, adquiriendo notoriedad y relevancia desde el comienzo, aunque no sin cierta crítica. Cada número constituyó una apuesta editorial particular que abordó sistemáticamente un campo particular de investigación. Su primer número estuvo dedicado al teatro, considerando el desarrollo de este en Chile y también su teorización. A partir del segundo número, en una sección denominada "Vida del Centro de Investigaciones Estéticas", donde se difunden las actividades y publicaciones de la casa de estudios, también son recogidas las recepciones que se hacen de esta nueva revista en diferentes medios escritos, que muestran un amplio apoyo a esta novedosa iniciativa de pensar el arte. Sin embargo, su carácter académico y a ratos erudito tuvo algunos reparos en la prensa de aquel entonces, lo que fue abordado por la misma revista en su tercera entrega, donde se presentaron en detalle no solo las críticas positivas a su aparición, sino también sus cuestionamientos. Así, en un apartado titulado "Dos críticas desfavorables", se presentan dos opiniones contrarias provenientes de frentes distintos: por un lado, una crítica de Nelson Osorio Tejeda en la revista Aurora (año IV, 1967), medio de divulgación cultural del Partido Comunista de Chile, en donde el crítico afirma que "no ha encontrado absolutamente nada positivo en el primer número" (345). La segunda crítica, de mayor alcance por ser atendida con más prolijidad y por ser trascrita en su totalidad, provino de la revista cultural PEC del 22 de septiembre de 1967, escrita por M.C.G., quien cuestiona el carácter erudito de la revista, aludiendo a la revisión del Padre Alfonso Escudero sobre la historia del teatro en Chile, como "excesivamente pasmosa", y agrega: "Leyendo así se va teniendo la sensación de que algo así como un cuarto de los habitantes de este país se ha dedicado al teatro" (346). También se cuestiona el trabajo "Crítica estética de la novela" de Radoslav Ivelic,

2 La excepción la constituye el año 1973, cuando, debido al golpe de Estado, la revista no apareció sino hasta el año siguiente. 


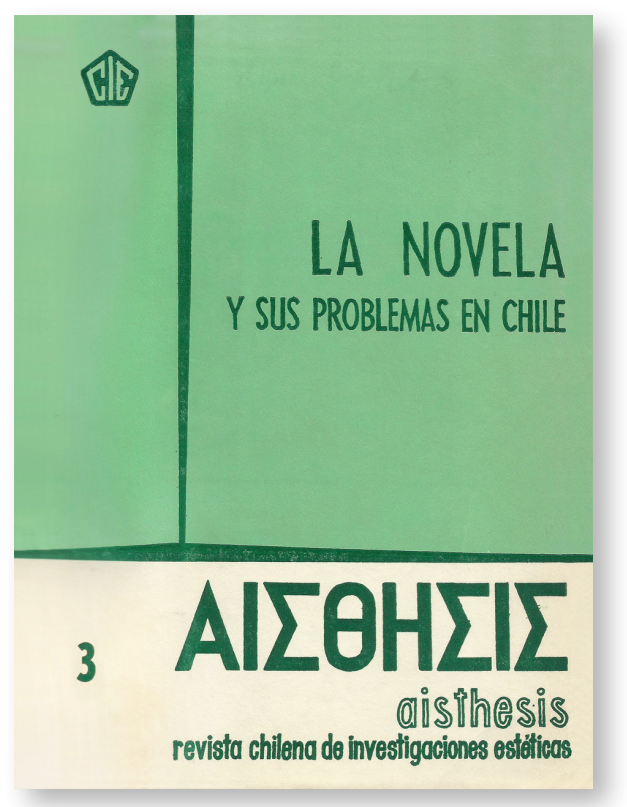

Portada del tercer número de la revista Aisthesis, dedicada a los problemas de la novela en Chile.

que, para $P E C$, constituye un ejemplo de ausencia de interés por acercar a un lector menos docto a la promoción del arte y la cultura. Curiosamente, esta crítica de PEC, revista ligada a la derecha chilena y posteriormente cuestionada por su filiación con el Instituto por la Libertad, financiado por la CIA, aduce a propósito del artículo de Ivelic "confesamos honradamente no entender nada..." (347), aunque no hay reparos para alabar el trabajo publicado en ese mismo número por el crítico Alone: "Desde este mismo punto de vista es que consideramos excelente, jugoso, vivaz e incisivo el artículo de Alone, que destaca casi sorpresivo en esta fronda" (347).

Esta polémica constituye todo un frente de batalla en la conformación de un campo disciplinar traspasado por la contingencia política de los años sesenta, la cual polemiza en torno al valor social y político de la cultura y las artes, decantado precisamente en el contexto de la reforma universitaria y las propuestas de las izquierdas latinoamericanas. Esto se pone de manifiesto no solo en esta discusión, sino en la afirmación de la misma revista, al hacer notar en su cuarto número, dedicado a la arquitectura y sus problemas en Chile, que el propio Departamento de Estética fue creado en 1969, en el marco de las reformas universitarias de la época (223).

La posición histórica de la revista fue tomando mayor visibilidad a medida que se profundizaban los cambios políticos en Chile con la Unidad Popular. Así, tenemos en 1970 un número dedicado a la poesía y sus problemas en Chile, donde participan, entre otros, Juvencio Valle, Efraín Barquero, Gonzalo Rojas, Jorge Teillier y Waldo 
Rojas. Podemos destacar el artículo de Alfonso Calderón dedicado al entonces reciente Premio Nacional, Nicanor Parra, y el memorable trabajo de Jorge Teillier, quien, haciendo eco del ímpetu político de la época, se refiere al papel de la poesía en su contingencia:

La burguesía ha tratado de matar a la poesía, para luego coleccionarla como objeto de lujo [...] El poema es un ser marginal, pero de esta marginalidad y de este desplazamiento puede nacer su fuerza: la de transformar la poesía en experiencia vital y acceder a otro mundo, más allá del mundo asqueante donde vive (281).

Se destaca el ímpetu social de este periodo, durante el cual las discusiones en torno a la función social de la cultura y las artes son abarcadas en varios medios, como las revistas Cormorán (1969-1970) y Nueva Atenea de 1970, dirigidas por Enrique Lihn; La quinta rueda (1972-1973); y los Cuadernos de la Realidad Nacional (CEREN), por nombrar algunos. En este sentido, se puede comprender los números de Aisthesis de 1970 y 1971, titulados "La educación por arte y sus problemas en Chile", I y II, respectivamente, donde se indaga en las formas de promoción y difusión del arte, y de cuál sería la función de la disciplina estética en el desarrollo de las artes y su estudio. Es en un artículo de Gaspar Galaz donde podemos notar esta preocupación: "El arte parece tener importancia; sin embargo, cabe preguntarse: ¿por qué? Esta interrogante ha cobrado significación sobre todo en nuestra sociedad de cambios, principalmente para darle otra vez a la actividad artística toda su fuerza social” (29).

Para continuar con una afirmación que traspasa todo el trabajo: "Comprender que el arte es un medio sensible de aprehender la realidad significa convertirlo en necesidad primaria para una sociedad" (29). De este modo, siguiendo la relación histórica del arte con la sociedad, se plantea el momento histórico específico del desarrollo de las sociedades capitalistas, que se reducen a un proceso de mercantilización y fragmentación que disocia a los hombres (34), lo que en la etapa social en que Chile se encontraba, significa expandir la visibilidad del arte para convertirla en una experiencia social, llegando a todos los rincones de la sociedad:

Quienes han disfrutado de las manifestaciones del arte han sido siempre minorías privilegiadas, situadas en un contexto social muy determinado. La gran mayoría está al margen de los procesos culturales y sociales que motivan al hombre de hoy. La educación y el arte son los medios por los cuales miles y miles de hombres pueden integrarse a los cambios, donde pretendemos que al arte le compete un papel importante como elemento formador. Tenemos que romper con lo que conocemos como "público culto" y hacer de nuestra sociedad un todo dinámico en que cada persona reciba lo necesario para actualizar cada vez más sus potencialidades, sin fronteras, sin diferencias de tipo cultural y económico, que son los ladrillos en la larga muralla que origina las diferencias sociales que separan a los hombres (Galaz 38). 


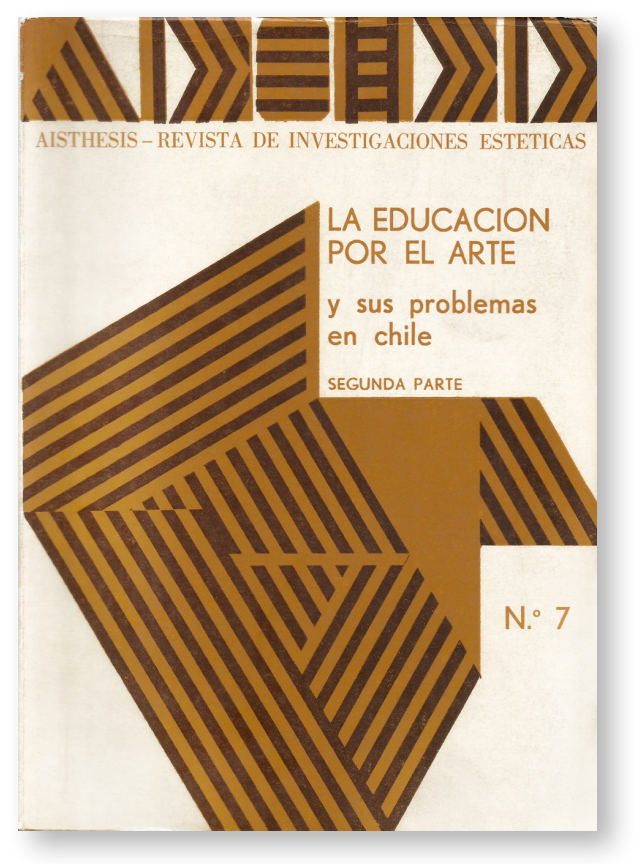

Portada del séptimo número de la revista Aisthesis, dedicada a la educación estética en Chile.

Como se puede notar de lo anterior, en este periodo de nuestra historia, tanto el arte como la cultura y la educación son considerados elementos indispensables para contribuir a una transformación social que atienda no solo a un cambio económico y social, sino sobre todo a una modificación en las estructuras de pensamiento dependientes para potenciar un sujeto colectivo, consciente y maduro ${ }^{3}$; propuesta que sufrió un duro revés con el golpe de Estado de 1973 para entrar en una etapa de sobrevivencia y limitaciones profundas, que también podemos notar en la historia de la revista.

\section{Una época oscura}

El golpe de Estado en 1973 arrasó con todas las prácticas político-culturales ampliamente desarrolladas durante la Unidad Popular. La imagen certera de libros distribuidos gratuitamente, o a muy bajos precios, por la editorial Quimantú de la Unidad

3 Podemos destacar las entrevistas realizadas por Gaspar Galaz en este mismo número, con la ayuda de Adriana Valdés, a cinco pintores (José Balmes, Eduardo Vilches, Nemesio Antúnez, Rodolfo Opazo y Mario Carreño). Las preguntas-temas realizadas indican nuevamente la preocupación por arte y la sociedad: 1 . El arte y su compromiso con la realidad; 2. ¿Un arte para "agradar" al público?; 3. El arte, hoy y aquí en Latinoamérica; y 4. El museo. 
Popular, en escuelas, barrios populares y sindicatos obreros, se convirtió de un golpe en silencio y prohibición, siendo la quema de los libros una de sus manifestaciones más gráficas. ${ }^{4}$ Las universidades fueron intervenidas, designando a militares como rectores, y hubo profesores detenidos, torturados, asesinados, exonerados o exiliados. La intervención de los medios masivos de comunicación fue contundente: ningún medio escrito, radio o canal de televisión que tuvo alguna cercanía con la Unidad Popular pudo seguir funcionando. Había que arrancar ese "cáncer marxista" ${ }^{2}$ que corroía las entrañas de Chile. Política de sanidad, de limpieza ideológica fue la que se inauguró con el golpe, proyecto que contó con la alianza de la fuerza militar, la derecha oligárquica local y la potencia intervencionista norteamericana que, en la dinámica de la Guerra Fría, se disputaba, junto con la Unión Soviética, el dominio mundial. Esta limpieza incluyó una serie de replanteamientos simbólicos que se superpusieron a los diseñados hasta el ascenso de la Unidad Popular. Por ejemplo, ese acto violento del 11 de septiembre fue acompañado por marchas militares transmitidas por las radios y dibujos animados en la televisión. Se impuso la limpieza de la ciudad y cortes de pelo y barba ${ }^{6}$. La Moneda quedó ardiendo, destruida, y se mantuvieron sus ruinas por más de diez años sin tocarlas, con lo que el edificio funcionó significativamente como un recordatorio permanente en la memoria colectiva del precio que se ha de pagar por intentar alterar el orden capitalista y hegemónico de dominación.

La intención clara de la dictadura fue la fundación de un nuevo Chile. Esto significó no solo deslegitimar el proyecto de la Unidad Popular, sino también considerarla como parte de un proceso más complejo y extendido en el tiempo de decadencia moral y social en Chile. Esto plantearía la necesidad de refundar el país y no simplemente restablecer las condiciones previas al gobierno de Allende. Jaime Guzmán, fundador del partido conservador UDI (Unión Demócrata Independiente) y gestor de la Constitución de 1981, refuerza este punto al asignar a la Junta Militar la legitimidad para llevar a cabo este proceso de construcción de un país distinto al que había: "Yo concuerdo con el gobierno en que lo sucedido implicaba la crisis total de un sistema

4 La universidad Diego Portales, como parte de la conmemoración de los cuarenta años del golpe militar, presentó la exposición "Libros quemados, escondidos, recuperados a 40 años del Golpe". En su presentación se afirma que "Muchos libros, por temor o represión, fueron quemados, escondidos o enterrados en miles de hogares e instituciones chilenas, configurando un espectro de autores, títulos y temáticas silenciadas, imposible ya de precisar y cuantificar. Se quemaron o destruyeron millones de libros, desde fábulas a literatura universal, pasando por escritores latinoamericanos o sencillamente publicaciones educativas, culturales, filosóficas o políticas. Es nuestro deber hacer este ejercicio de memoria y recuperación a partir de una exposición que se abre como campo de investigación de nuestra historia" (Libros quemados).

5 El mismo 11 de septiembre de 1973, el General Gustavo Leigh, Comandante en Jefe de la Fuerza Aérea, junto a los demás integrantes de la Junta Militar, establece la noción de guerra interna con estas palabras: “Tenemos la certeza, la seguridad de que la mayoría del pueblo chileno está contra el marxismo, está dispuesto a extirpar el cáncer marxista hasta las últimas consecuencias" (Guzmán).

6 Una nota del diario oficialista El Mercurio, relataba: "Estudiantes y jóvenes trabajadores han acudido como de común acuerdo a cortar sus cabelleras demasiado frondosas en Magallanes. Una nueva 'onda' se impone rápidamente entre la juventud: el pelo corto y bien aseado. Las peluquerías locales deben enfrentar para atender a quienes quieren ser primeros en exteriorizar, en sus propias personas, el espíritu viril y renovador que recorre la República” (El Mercurio 1973, 25. Citado por Errázuriz, 145). 
y que por lo tanto hay que avanzar hacia la creación de una nueva democracia, y no retroceder al restablecimiento de lo que había" (11).

La desinstalación de la escena artística cultural, considerada como "apagón cultural", logró que los registros simbólicos, los agentes culturales y los espacios de difusión, es decir, el campo artístico y cultural en su totalidad, fueran arrasados y con ello todas las formas de representación comenzaran a ser parte de un registro serial de valoración política por parte de los agentes de la dictadura. En adelante, la vida social y cultural fue codificada desde un esquema dicotómico entre el pasado inmediato, representado por la izquierda y la Unidad Popular en particular; y el nuevo orden militar, destinado a erradicar "el cáncer marxista" y el "caos institucional y moral" dejado por la UP, y a recuperar los valores morales y el orden perdido. Se consideró necesaria la intervención en las construcciones simbólicas que constituyeron una poética de la Unidad Popular, de modo que el campo cultural del arte y las humanidades fue notoriamente objeto de limpieza ideológica, precisamente por la prolífica relación que se produjo entre arte y política en los casi tres años del gobierno de Salvador Allende. El circuito artístico que se gestó durante el gobierno de la up fue desmantelado y sus protagonistas perseguidos, detenidos o exiliados. Con el toque de queda y la represión sistemática, las brigadas muralistas, que tuvieron una fuerte presencia durante la UP, dejaron de pintar. Los grandes artistas que posibilitaron un campo artístico heterogéneo fueron súbitamente desmembrados del apoyo estatal y de la fuerza movilizadora de la vía chilena al socialismo, lo que supuso la mera sobrevivencia del arte pictórico en los escasos espacios disponibles para el desarrollo cultural.

El golpe militar interrumpió el monopolio desequilibrante de la pintura. Los pintores más importantes abandonaron voluntaria o involuntariamente el país: Antúnez, Balmes, Barrios, Vial, Martínez Bonati, Núñez, Israel, Ortúzar, etc., junto a un número considerable de pintores jóvenes. De esta manera, el territorio de la pintura quedó casi despoblado e, igualmente, su principal centro de enseñanza: la Facultad de Bellas Artes de la Universidad de Chile. Se hizo un relevo a marcha forzada para reemplazar a exiliados y exonerados, revisar contenidos, depurar bibliografías y neutralizar al máximo cualquier aspecto conflictivo de la enseñanza artística. A la facultad ingresaron decanos proclives al régimen militar, nombrados verticalmente por los rectores delegados de turno. Era obvio que en una universidad "vigilada" -para emplear el término de Jorge Millas- difícilmente la docencia artística podía aspirar a algo más que a una enseñanza escolarizada, con alumnos pasivos sin capacidad de diálogo, discusión y crítica ¿Los años 80 no han sido representativos de una generación replegada, sin inserción definida en el contexto represivo del régimen militar? (Galaz e Ivelic 39).

En este escenario desolador, las condiciones en las que la revista Aisthesis siguió su curso fueron de la más extrema precaución y menesterosidad. En este contexto de precariedad 


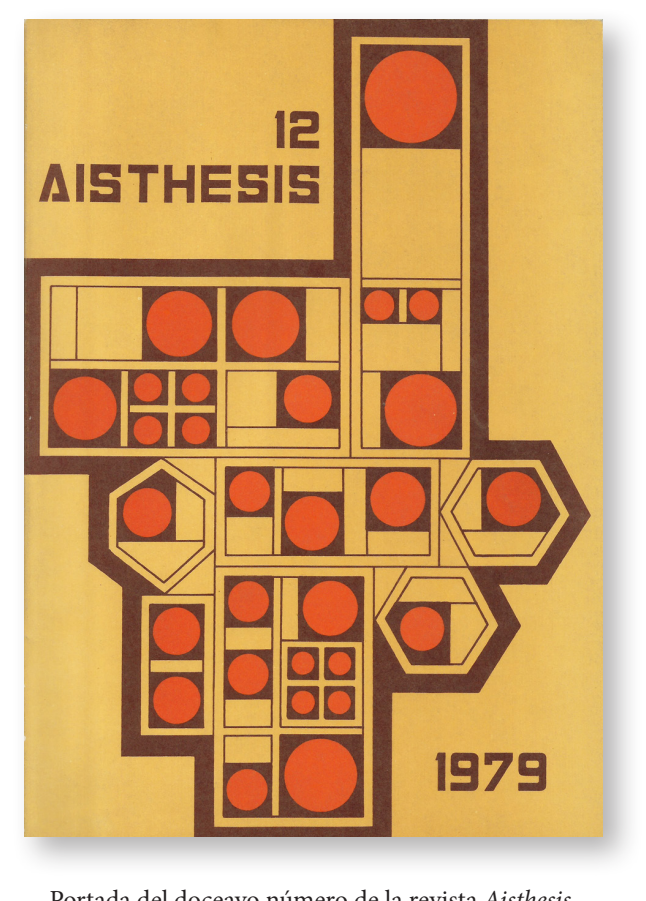

Portada del doceavo número de la revista Aisthesis.

y abandono es posible entender que el número de 1973 no viera la luz y que el número 8, dedicado a "La música y sus problemas en Chile", apareciera recién en 1974. Junto con cambiar la imagen que tuvo hasta 1972 (y que de allí siguió modificando constantemente hasta el número 18, de 1985, cuando adquiere un formato más o menos regular), la revista también cambia sus planteamientos, profundizando en el análisis teórico de carácter global, mucho más desprendido de la contingencia social que aludimos anteriormente, tal como lo demuestran los artículos de Raimundo Kupareo, "La armonía musical y la armonía humana", y de Jorge Montoya, "La experiencia musical como experiencia trascendente", por nombrar algunos. Sin duda, la situación de una constante vigilancia junto con la drástica reducción del interés por las artes y las humanidades, sometidas al ojo vigilante que las consideraba peligrosas por su vinculación con el proceso político de la Unidad Popular, hicieron que la revista viviera de aquí en adelante, y hasta la llegada de la democracia en 1990, un proceso de sobrevivencia precaria, donde se puso en riesgo incluso su periodicidad -tanto el número 9 como el número 13 abarcan dos años en vez de uno; 1975-76 y 1980-81, respectivamente.

Sintomático de esta realidad es que pese a que los números de la revista versan, por ejemplo, acerca de "La música y sus problemas en Chile" (n8, 1974) o "La pintura y sus problemas en Chile" ( $\left.n^{\circ} 9,1975-76\right)$, no hay en ellos ninguna referencia ni a la música de la Nueva Canción Chilena o a la afiliación política que tuvo el arte durante los tres años de la Unidad Popular. En el caso de la música, se rescata 
esencialmente la historia de la música "docta" (en un artículo de Letelier Llona); o bien, en un artículo de Manuel Dannemann, se escribe acerca del folklore, pero solo en relación con el desarrollo de los estudios en torno a la música de las culturas indígenas, agrupadas por zonas geográficas, sin ninguna mención a la producción artística ni a las investigaciones sobre el folklore vivo que realizaron, por ejemplo, Violeta Parra o Margot Loyola. En el caso de la pintura, donde Galaz e Ivelic en el número 9 interrogan a algunos artistas (Carmen Aldunate, Mario Carreño, Rodolfo Opazo, entre otros) para su artículo "La pintura: su candente realidad", podemos notar que hay algunas respuestas que se distancian de la posición políticamente comprometida que el arte mantuvo antes del golpe; por ejemplo, en la intervención de Rodolfo Opazo, quien dice valorar el cosmopolitismo del arte contemporáneo sobre el intento de "expresar lo americano" (192), agregando que "si bien no soy contrario a integrarme a un modo de expresión propio, tengo mucho más interés de que mi obra esté conmigo como parte de un todo" (192). El mismo tono de distanciamiento con el periodo anterior lo vemos en Carlos Aldunate cuando afirma que "el arte fue y será siempre para un círculo reducido. Jamás se debe rebajar el lenguaje para hacerlo comprensible" (194).

La primera mitad de los ochentas no fue muy diferente; es posible notar las restricciones al contenido de la revista y la precariedad de su producción durante ese periodo por la escasez de trabajos publicados y la reiteración de nombres. A pesar de ello, Aisthesis comienza a recobrar, pálidamente al principio, un cierto aire de frescura. El carácter monográfico que tuvo la revista desde su origen y que llega hasta su novena entrega, se retoma nuevamente con el número 13, de 1983, dedicado al cine, donde el trabajo de David Vera, "Cine chileno: sesenta y ocho años de filmaciones", realiza una interesante reflexión acerca de la historia de la producción cinematográfica chilena, con la particularidad de no escabullir clasificar al nuevo cine chileno, realizado durante la Unidad Popular, como un momento fundamental, y contraponerlo con la pobreza de la producción cinematográfica posterior al golpe. Es así como el cine, el folklore ${ }^{7}$, las artes visuales y la crítica literaria comienzan a adquirir mayor visibilidad y los trabajos publicados muestran mayor consistencia. Sin embargo, no es sino hasta el número 18, de 1985, que la revista adquiere una portada que perdura hasta 1999, lo que resulta significativo, pues su variabilidad gráfica revela sintomáticamente los duros y complejos momentos que la revista estaba viviendo. Durante esta segunda mitad de la década, los trabajos que se publican también van adquiriendo un gesto de resistencia. Por ejemplo, Ivelic clasifica las artes plásticas como fenómeno cultural, donde la cultura estaría estrechamente ligada a la historicidad del hombre y posee, por tanto, una conexión inexorable con el pasado, además de un carácter intersubjetivo, definido por su comunicabilidad:

7 Véase los números monográficos 15, 16, 20 y 22. 


\begin{abstract}
Esta finalidad de la cultura supone instaurar una coexistencia pacífica y respetuosa; es impensable sin tolerancia y sin justicia. De ahí que una cultura impuesta, además de atentar contra la libertad del hombre, pone obstáculos al proceso formativo de la propia cultura que, en su complejidad, desde la profundidad del saber hasta el comportamiento más elemental, nace de la colaboración de todos los hombres (29).
\end{abstract}

Estas afirmaciones, puestas en el contexto de una dictadura militar, suponen una fuerte crítica al diseño que se estaba gestando en aquella época, concluyendo sin rodeos que el arte vendría a ser una experiencia transgresora, pues pone en ejercicio la práctica de la libertad.

\title{
La revista en la transición postdictatorial
}

En 1990, coincidente con el proceso político de reincorporación de la democracia en Chile, llamado "transición", la revista inicia su número 23 con una mención de Fidel Sepúlveda a sus veinticinco años de historia:

Para otros contextos, 25 años pueden parecer una duración pequeña. Para la práctica cultural chilena, donde revistas como Aisthesis alcanzan a aparecer una, dos, tres veces y desaparecen, este durar lo estimamos digno de atención, de reconocimiento y de apoyo.

Ha sido una presencia y una acción en pro de la cultura y del arte en una realidad donde esto no preocupa. Se lo considera facultativo, prescindible. La reflexión, el estudio acerca del arte y su función en la sociedad no se valora como artículo de primera necesidad.

Estar presentes durante 25 años denota un compromiso asumido responsablemente. Se lo ha cumplido trabajando en la investigación, interpretación y valoración de la creación artística chilena, individual y comunitaria, tradicional y contemporánea, entendiendo que en esta área acontece lo más relevante de nuestra identidad.

Efectivamente, ya cumplir 25 años, pasando por los convulsos tiempos revolucionarios y luego sobreviviendo a diecisiete años de dictadura militar, era digno de elogio. Con la transición, el país se vuelca rápidamente al examen de lo vivido. Bajo este mismo pathos, la revista comienza un periodo de balances y análisis de las diversas expresiones artísticas y cómo fueron permeadas por la violencia militar que cercenó una historia de constante colaboración. Comprender cómo se ha articulado, modificado y reflexionado el arte en diferentes etapas, significó un momento clave de la revista para evaluar el desarrollo de la estética. Las entregas 23 y 24 abordan este balance con "25 años de artes en Chile I: arquitectura, artes visuales, cine, música" y "25 años de arte en Chile II, poesía, teatro, narrativa”, respectivamente. 
La evaluación de las artes visuales estuvo a cargo de Galaz e Ivelic, quienes brillantemente recorren sus transformaciones desde los años sesenta, cuando el arte fue pasando desde la pintura tradicional hacia una nueva intensidad, tomando diversos soportes como telas, cartón o madera y diversas texturas como pintura trapo, brocha directamente con la mano y fotografías pegadas como collage, hacia un arte comprometido que recupera materiales provenientes de la "marginalidad social chilena invadiendo los espacios artísticos en un simulacro destinado a despertar la conciencia social, a superar la inactividad visual y mental que prevalece habitualmente cuando se mira un cuadro o una escultura" (Galaz e Ivelic 37). El golpe suspende esa historia y la pintura es sustituida por las artes visuales que, haciendo uso del cuerpo, la ciudad, el video, la fotografía y la reflexión, alteran los signos del arte y sus modos de circulación: El medio artístico nacional se vio completamente alterado con la sustitución del cuadro colgado en la pared por la presentación del propio cuerpo del artista como soporte de arte (arte corporal), o bien por la especulación y manipulación con los objetos cotidianos dispuestos en el espacio de una galería (instalación), o con el desplazamiento del trabajo de arte al espacio urbano al intervenir sus vías de circulación, al alterar sus señales de tránsito o sus enclaves marginales (acciones de arte). Este fenómeno transgresor puso de manifiesto, además, una opción crítica respecto al circuito institucional de exhibición, en un intento por expandir el territorio ocupado más allá de los límites galerísticos y museales (Galaz e Ivelic 40).

Finalmente, se sitúa la escena artística de los ochentas, cuando, enmarcados en el sino del fin de las utopías, los artistas se repliegan en sí mismos, en lo que llaman "estética de la informalidad" (46), donde el arte contextual previo es "reemplazad[o] por un cosmopolitismo anónimo" y está sujeto a una globalidad internacional que "nos ha llevado de nuevo a una pintura dependiente, que orbita alrededor de los paradigmas hegemónicos" (46).

En cuanto a la narrativa, Sergio Saldes B., en "Narrativa chilena 1966-1991 en busca de continuidad e integración”, busca, como su título lo indica, una continuidad entre la generación pre-golpe, la de 1972 (Poli Délano, Mauricio Wacquez, Cristián Huneeus, Carlos Morand, Fernando Jerez y Antonio Skármeta), y la producción narrativa en dictadura. Saldes plantea que Cristián Huneeus y Diamela Eltit son autores capaces de superar las carencias que Ariel Dorfmann, en su artículo de 1966, "Perspectivas y limitaciones de la novela chilena actual", había vislumbrado en la narrativa de la época, vale decir, la despreocupación por los problemas reales de la sociedad, una impostura en la asunción de técnicas, modos de expresión y lenguajes nuevos, y la sobrevivencia de una representación criollista.

En Huneeus y Eltit parece estar, entonces, la respuesta que Dorfman exigía de parte de la narrativa chilena en 1966 y 1970: una narrativa comprometida con la realidad del país, y a la vez revolucionaria por medio del lenguaje; en Huneeus 
y Eltit encontramos, también, el lazo de unión con la literatura latinoamericana postboom, la literatura de la Generación a la que estos escritores pertenecen, en términos cronológicos. (Saldes 72)

A partir del año 2006, la revista comienza un nuevo ciclo de periodicidad, publicándose dos veces al año hasta la actualidad y continuando así con su vitalidad y atención al registro y análisis de diversas expresiones artísticas, como la literatura, las artes visuales, el cine, el teatro, la música, la artesanía y la danza, entre otras. De este modo, afianza su carácter multidisciplinario, el cual, como señala su política editorial, comprende "un diálogo con otras áreas de estudio como la historia, teoría, la crítica de Arte y la crítica cultural".

Quienes creemos en la importancia de la cultura y el arte lo hacemos con la convicción de que las manifestaciones culturales, en sus diversas corrientes, tiempos y tensiones, contribuyen al fortalecimiento de la humanidad. Al estar arraigado en el plano simbólico y sus imaginarios, el arte intensifica un sentido de comunidad que nos liga a los otros como partes de un sistema complejo de comunes, de una identidad movible y múltiple. Diríamos que la somera revisión de estos cincuenta años de la revista nos confirma el esfuerzo de Aisthesis por promover, reflexionar y conformar un campo disciplinar, entendido como una disputa y un ejercicio histórico de construcción de un objeto de estudio, su análisis y el reconocimiento de sus prácticas y sus modos de comprensión. El desarrollo de la estética en Chile, por tanto, pasa por una comprensión de la revista y también de la institucionalidad que la sustenta, como un ejercicio inédito de constitución de la disciplina estética en cuanto campo de investigación propio y no como sub-campo de la filosofía, con lo que adquiere una propuesta heterogénea y multidisciplinaria. Por otro lado, desde su origen, la propuesta editorial de la revista ha estado dirigida a comprender no solo los principales debates y propuestas teóricas globales sobre el arte, sino sobre todo a pensar el quehacer artístico en el contexto particular de nuestro país, lo que la hace eminentemente más atenta, aunque no limitada, al desarrollo de prácticas artísticas locales y fuertemente ligada a los procesos sociales y políticos que han afectado nuestra historia.

Este trabajo está lejos de abarcar la larga trayectoria y amplia diversidad de tópicos que Aisthesis ha logrado abordar en todos estos años. La lectura de este tipo de revistas, que se configuran como instancias colectivas de diálogo con su tiempo y definidas por la pluralidad de voces que las componen, siempre supone una selección, definida por un lector que se centra en algunos ejes que considera determinantes, dejando otros sin la debida atención. El tratamiento de una revista como Aisthesis requiere no solo de su clasificación y análisis, sino también de un trabajo colectivo que logre abordar de manera menos incompleta la conformación de un campo disciplinario, especialmente cuando su historia es traspasada por nuestra propia contingencia. 


\section{Referencias}

Anónimo. "Libros quemados, escondidos, recuperados." Universidad Diego Portales 2013. Web. 26 de agosto 2013.

Anónimo. "Vida en el Centro." Aisthesis 3 (1968): 342-354. Impreso.

Beigel, Fernanda. "Las revistas culturales como documentos de la historia latinoamericana." Utopía y Praxis Latinoamericana. Revista Internacional de Filosofía Iberoamericana y Teoría Social 8.20 (2003): 105-115. Impreso.

Bourdieu, Pierre. Campo de poder, campo intelectual. Buenos Aires: Editorial Montressor, 2002. Impreso.

Dannemann, Manuel. "Estudios sobre música folklórica en Chile." Aisthesis 8 (1974): 269-305. Impreso.

Errázuriz, Luis Hernán. "Dictadura militar en Chile: Antecedentes del golpe esteticocultural." Latin American Research Review 44.2 (2009): 136-157. Impreso.

Galaz, Gaspar. "La fuerza social del arte." Aisthesis 6 (1971): 29-38. Impreso.

Galaz, Gaspar y Milan, Ivelic. "Apuntes para una reflexión: artes visuales en chile (1960-1990)." Aisthesis 23 (1990): 33-47. Impreso.

---. "La pintura: su candente realidad." Aisthesis 9 (1975-76): 185-202. Impreso.

Galaz, Gaspar y Adriana Valdés. “Experiencias de seis pintores.” Aisthesis 6 (1971): 153-160. Impreso.

Gilman, Claudia. "Las revistas y los límites de lo decible: cartografía de una época." La cultura de un siglo: América Latina en sus revistas. Buenos Aires: Alianza Editorial, 1999. 461-468. Impreso.

Guzmán, Jaime. "Sal y Pimienta." LA TERCERA de La hora. Santiago: 1979. 10-11. Impreso. Ivelic, Milan. "Las artes plásticas en la cultura." Aisthesis 18 (1985): 27-30. Impreso.

Kupareo, Raimundo. "La armonía musical y la armonía humana." Aisthesis 8 (1974): 15-22. Impreso.

Letelier Llona, Alfonso. "Cosideraciones sobre la música chilena." Aisthesis 8 (1974): 241-254. Impreso.

Montoya V., Jorge. "La experiencia musical como experiencia trascendente." Aisthesis 8 (1974): 23-39. Impreso.

Rancière, Jacques. El inconsciente estético. Buenos Aires: Del estante editorial, 2005. Impreso.

Saldes B., Sergio. "Narrativa chilena 1966-1991. En busca de continuidad e integración". Aisthesis 24 (1991): 67-78. Impreso.

Sarlo, Beatriz. "Intelectuales y revistas: razones de una práctica". América. Cahiers du CRICCAL 9/10 (1990): 9-15. Impreso.

Schwartz, Jorge y Roxana Patiño. "Introducción”. Revista Iberoamericana Lxx 208-209 (2004): 647-650. Impreso.

Sepúlveda, Fidel. "25 años de arte en Chile. Arquitectura, Artes Visuales, Cine, Música”. Aisthesis 23 (1990): 7. Impreso.

Teillier, Jorge. "Sobre el mundo donde verdaderamente habito". Aisthesis 5 (1970): 279-284. Impreso. 